\title{
Postgenomic drug discovery
}

The now-fashionable use of the tools and principles of developmental biology in what is called "postgenomic" drug discovery (see p. 1220 ) is classic biotechnology. The genome project has spewed forth data, and while bioinformatics grapples with the task of collating and curating this information in such a way that it can be used by the research community at large (see pp. 1222 and 1253), and molecular genetics is being used to attach patients to "disease genes," (see p. 1249), ideas derived from developmental biology are being brought to bear on the enormous problem of translating genes and pathways to physiological structures and functions.

Still in its infancy, the premise is to integrate genetics and model systems used in developmental biology to unravel biochemical networks involved in human disease. This new drug technology is being used to search for highly conserved networks to determine which genes make good targets for new therapies. Once found, biotechnology companies hope to regenerate diseased organs and tissues by inducing the "right" set of genes to restore function. These companies are retracing the early steps of biotechnology companies that produced inducing factors such as EPO. This time the challenge is to find highly specific molecules whose mechanism of action is much less direct.

To accomplish this, biotechnology must reinvent and reinvigorate itself by feeding off the basic research sciences. This is not to say that biotechnology does not benefit the basic biological community, but in large part, the arrow goes the other way. This latest use of research spawned in the basic community is a reminder of the need for continued, enthusiastic funding of basic research that has no product or obvious monetary endpoint. No single pharmaceutical company could possibly have funded the basic zebrafish development studies or studies of the embryological development of worms and fruit flies, model systems that now-with the discovery of ever more genes that are shared across species-look so appealing and that may some day play a significant role in the business of sorting out drug leads and targets based on developmental pathways. Biotechnology companies themselves can only afford to participate in this kind of deep research insofar as they can explain how they intend to use it.

Although not without its pitfalls (see p. 1225), genetics has served biotechnology well, having spawned any number of businesses and potential products. And now the use of developmental biology should certainly help in the attempt to identify and manipulate functional pathways in the service of new drug and therapies.

Big breakthroughs require the kind of nontargeted, basic research upon which this new drug technology will be developed. It will ensure that there will be a continuous supply of ideas and tools available to sort out the critical variables in the increasingly complex process of developing effective and safe new drugs for chronic and multifactorial diseases.

\section{Vorsicht emptor!}

Qiagen's listing on the Neuer Markt, Frankfurt's junior stock exchange, will doubtless foment the biotechnology epidemic that seems to be infecting Germany. Two of Qiagen's venture capital investors, TechnoVenture Management and S-Kapital sold 2.3 million of their shares in Qiagen at the end of September at around $\$ 47$ each. Qiagen's shares have thus tripled in value since the company's initial public offering on Nasdaq in June 1996. The company's chief financial officer expects trading in shares on the German market to be brisk.

All this sounds very encouraging for German investors in biotechnology. By all reports, billions of deutsche marks have been earmarked for early stage biotechnology investments. Pension and insurance fund managers in Germany are eagerly waiting for opportunities to put their money into German companies as they go public; Qiagen is currently their only option.

The only problem is that it might not take much to burst biotechnology's bubble in Germany, and elsewhere in Europe, too.

Qiagen, like several other companies in Europe, is a national champion of biotechnology. Genset has the role in France; Innogenetics in Belgium. The colors of biobusiness and its hopes are pinned firmly to them. Biotechnology companies are being sighted across stock exchanges all over Europe. But they are rare birds. Biora and only Biora is quoted on the Stockholm exchange; Neurosearch is the epitome of biotechnology in Copenhagen. Even in the UK which has a score of public bioscience companies, the hopes of British investors rest heavily on British Biotech and the clinical progress of its anticancer drug, Marimastat.

This period of bio enthusiasm in Europe should force the price of shares in these lonesome champions up. God forbid, they may already be overpriced. If they fall, biotechnology across an entire nation falls. The markets for public biotechnology stocks in Europe have not yet reached anywhere like the stability and maturity of their counterparts in the US. That is, of course, just a euphemistic way of saying that many investors are naive and sentimental. They operate neither logically nor statistically. Their money may be cheap but it is also fickle. It will not be as readily offered to the next biotechnology opportunity.

Biotechnology companies should welcome Europe's new stock exchanges and the newly enlightened attitudes of investors. But they should tread carefully. Companies that soon expect to make initial public offerings in Europe-and there are several-need to resolve a dilemma. On the one hand, obligations to existing shareholders mean that they should price shares high to raise the maximum amount of money. On the other, unrealistic pricing will subsequently alienate investors from biotechnology in general, and especially from reinvestment in company that took their money the first time. Getting the balance right over the next few months could determine the pattern of European investment in biotechnology over the next few years. 